\title{
Prenatal exposure to tobacco and alcohol are associated with chronic daily headaches at childhood
}

\author{
A population-based study
}

\author{
Marco Antônio Arruda', Vincenzo Guidetti², Federica Galli², \\ Regina Célia Ajeje Pires de Albuquerque ${ }^{3}$, Marcelo Eduardo Bigal ${ }^{4,5}$
}

\begin{abstract}
The influence of prenatal events on the development of headaches at childhood has not been investigated and is the scope of our study. Of 2,173 children identified as the target sample, consents and analyzable data were provided by 1,440 (77\%). Parents responded to a standardized questionnaire with a validated headache module and specific questions about prenatal exposures. Odds of chronic daily headache $(\mathrm{CDH})$ were significantly higher when maternal tabagism was reported. When active and passive smoking were reported, odds ratio (OR) of $\mathrm{CDH}$ were 2.29 [95\% confidence intervals $(\mathrm{Cl})=1.6$ vs. 3.6)]; for active tabagism, $\mathrm{OR}=4.2(95 \% \mathrm{Cl}=2.1-8.5)$. Alcohol use more than doubled the chance of $\mathrm{CDH}$ (24\% vs. $11 \%, \mathrm{OR}=2.3,95 \% \mathrm{Cl}=1.2-4.7$ ). In multivariate analyses, adjustments did not substantially change the smoking/CDH association. Prenatal exposure to tobacco and alcohol are associated with increased rates of $\mathrm{CDH}$ onset in preadolescent children.

Key words: headache, migraine, childhood, prenatal exposure, tobacco, alcohol.
\end{abstract}

Tabagismo e ingestão alcoólica pré-natal estão associados à cefaleia crônica diária na infância: um estudo de base populacional

\section{RESUMO}

A influência de eventos pré-natais na fisiopatogenia das cefaleias na infância ainda não foi investigada e é o objetivo desse estudo. Da amostra-alvo de 2.173 crianças, um consentimento pós-informado e dados suficientes para as análises foram obtidos de 1.440 (77\%). Os pais responderam a um questionário padrão com um módulo de cefaleia validado na população brasileira e questões específicas sobre antecedentes pré-natais. $O$ risco de cefaleia crônica diária (CCD) foi significativamente maior nas crianças cujas mães fumaram durante a gestação. Quando presentes tabagismo ativo e passivo, o risco (OR) de CCD foi de 2,29 [intervalo de confiança (IC) de 95\%=1,6-3,6)]; para tabagismo ativo, $\mathrm{OR}=4,2$ (IC 95\%=2,1-8,5). O uso de álcool durante a gestação dobrou o risco de CCD (24\% vs. $11 \%, O R=2,3, I C 95 \%=1,2-4,7)$. Nas análises multivariadas, os ajustes não modificaram, substancialmente a associação entre tabagismo materno durante a gestação e CCD. A exposição pré-natal ao tabaco e ao álcool encontra-se associada à CCD de início na infância. Palavras-chaves: cefaleia, enxaqueca, migrânea, infância, tabaco, álcool.

\section{Correspondence}

Marco Antônio Arruda

Av. Braz Olaia Acosta 727/310

14026-040 Ribeirão Preto SP - Brasil

E-mail: arruda@institutoglia.com.br

Received 30 March 2010

Received in final form 21 July 2010

Accepted 28 July 2010
The epidemiology of frequent headaches in the pre-adolescent pediatric population is poorly known, but limited ev- idence suggests that headaches on more than 10 days per month happen in over $4 \%$ of this population ${ }^{1}$. This relatively high

${ }^{1} \mathrm{MD}$, PhD, Director, Glia Institute, Ribeirão Preto SP, Brazil; ${ }^{2} \mathrm{MD}$, Department of Child and Adolescent Neurology, Psychiatry and Rehabilitation, Sapienza University of Rome, Rome, Italy; ${ }^{3} \mathrm{MD}, \mathrm{M}$ Sci., Department of Pediatrics, São José do Rio Preto School of Medicine, São José do Rio Preto SP, Brazil; ${ }^{4} \mathrm{MD}$, PhD, Global Director for Scientific Affairs, Neuroscience, Merck Research Laboratories, Whitehouse Station, NJ, U.S.; ${ }^{5} \mathrm{MD}, \mathrm{PhD}$, Department of Neurology, Albert Einstein College of Medicine, Bronx, NY, U.S. 
prevalence is important for several reasons. First, because secondary headaches are more common in young children than in adolescents or adults ${ }^{2}$, children with frequent headaches should be assessed for ominous etiologies, and rendered a proper diagnosis. Second, for a number of disorders, early age of disease onset is associated with increased genetic predisposition and refractory outcomes $^{3}$. For migraine, early onset of disease in the proband, as well as the severity of migraines, were associated with higher levels of family aggregation . Additionally, when contrasted to adults, adolescents with chronic daily headache $(\mathrm{CDH})$ were more likely to have developed the disease without exposure to environmental risk factors (e.g. medication overuse) $)^{4-6}$.

Increased vulnerability of pediatric subpopulations to certain diseases may reflect a combination of stronger biological predisposition, pre-natal exposures, or early life exposures/comorbidities ${ }^{7}$. Among the prenatal exposures, tabagism and exposure to alcohol are of interest. Nicotine targets specific neurotransmitter receptors in the fetal brain, eliciting abnormalities of cell proliferation and differentiation, leading to shortfalls in the number of cells and eventually to altered synaptic activity ${ }^{8}$. For alcohol, alterations in fetal biometric measurements were reported in those with consistent exposure during pregnancy 9

The importance of tabagism and of alcohol use in the development of chronic headaches in adults is controversial. While some studies reported an association between headaches and tabagism ${ }^{10}$, others failed to demonstrate it, or to show any association with alcohol exposure $^{11}$. Evidence about the importance of prenatal exposures on the onset of chronic forms of headache is still missing. Accordingly, herein we take advantage of a large ongoing pediatric epidemiological study (Attention Brazil Project), in order to conduct a case-control study assessing whether exposure to tobacco and alcohol are associated with headaches later on life after adjustments for pre-natal and post-natal potential covariates.

\section{METHOD}

\section{Overview}

This study was conducted as part of the AttentionBrazil Project, a large ongoing population study aiming to investigate the mental health of children and adolescents in Brazil ${ }^{12}$. Details of the project have been described ${ }^{1}$. In brief, this project consists of two phases. In Phase 1 (pilot phase), target sample consisted of all children from 5 to 12 years registered in the public school system of a city with 32,862 inhabitants (Santa Cruz das Palmeiras, $\mathrm{SP}$, Brazil ${ }^{13}$. In Phase 2, a Brazilian representative sample is currently being enrolled and face-to-face interviews are being conducted. Data reported herein was obtained from Phase 1 of the study.

\section{Characteristics of the sample}

As per the city records, a total of 2,173 children younger than 12 years were registered in the elementary school in the year of the study (2008). All of them were contacted (target sample). Of them, 1,870 gave consent forms (86\%) and 1,440 (77\% of those consenting and $66.3 \%$ of the target sample) provided data with complete demographic and headache information, as well as information on exposures during pregnancy (see below).

\section{Questionnaire}

Direct interviews were made with the children, one with their parents, and their teacher. For this study, we only included cases where the mother was the responding parent. The standardized questionnaire consisted of 97 questions, divided in modules assessing different domains. The first component of the questionnaire (26 questions) assessed demographic features (including socioeconomic variables) using the same established criteria of the demographic census. We then asked about pregnancy antecedents (see below), developmental deficits of the child and behavioral features.

The headache module of the questionnaire consisted of 10 questions, assessing the distinguishing features required for headache diagnosis, such as headache characteristics, frequency of pain, nausea, photophobia, phonophobia, duration of the episodes, consumption of analgesics, etc. Further, we also asked about behaviors related to pain. The questionnaire followed the ICHD-2 classification criteria for primary headaches, but also assessed headache frequency over the past month and year, and other headache parameters ${ }^{14}$. Herein, since we assessed influence of exposures on headache frequency, we don't present the ICHD-2 classification, which was reported separately ${ }^{1}$. Instead, we stratified headache sufferers according to frequency, as described below. A similar version of the questionnaire had been previously tested by means of 40 telephone interviews conducted with patients from an outpatient headache clinic (individuals could have any form of headache or be in remission). Diagnoses were compared with those obtained during personal consultation with a specialist. Diagnostic agreement happened in $97.5 \%$ of cases $^{15}$.

Finally, questions on headache affecting the parents (ever vs. never, in the past year, and number of headache days over a typical month) were asked. Other questions focused on attention problems (e.g. Child Behavior Checklist) , and were not considered for the current study.

\section{Pregnancy antecedents}

A total of 7 questions focused on pregnancy antecedents and were responded to by the mother. They asked: [1] If the mother received prenatal care; [2] If the mother 
smoked during pregnancy; [3] If the father or other individuals leaving with the mother smoked during her pregnancy; [4] Maternal alcohol use during pregnancy; [5] Illicit drug use during pregnancy; [6] Hypertension during pregnancy; [7] Length of pregnancy; [8] Type of delivery (vaginal, cesarean, other).

\section{Statistical analyses}

Data from subjects 5-12 years were analyzed. Based on the headache responses, individuals were categorized in different ways, as follows: [1] No headaches over the past year; vs headaches; [2] No headaches, episodic headaches (headaches in the past year and 1-14 headaches per month), and chronic daily headaches (CDH, 15 or more headaches per month); [3] No headaches (NH), low frequency headaches (1-8 headaches per month) and high frequency headaches ( 9 or more headaches per month); [4] No headaches, low frequency episodic headaches (LFEH) headaches in the past year and less than 5 days of headache per month; intermediate frequency episodic headaches (IFEH) from 5-9 headaches per month; high frequency episodic headaches (HFEH) from 10-14 days of headache per month; [5] CDH. Although the formal definition of $\mathrm{CDH}$ calls for 3 months of assessment, we restricted our recall to the past month, as described previously ${ }^{4}$ in order to avoid recall bias.

The reason we categorized differently was to assess whether eventually positive risk factors were associated with any headache status (e.g. with headaches overall) or with specific headache status (e.g episodic headaches, HFEH, CDH). Since preliminary data on the topic were not available, we took a more exploratory approach on purpose.

Tabagism during pregnancy was categorized as active (only the mother), passive (only the partner or other household member), both (active and passive), either (active or passive) or no tabagism (neither active nor pas- sive). Use of alcohol was self-reported as yes or no. Other variables were self-reported.

We estimate the crude prevalence of headache categories as a function of gender, tabagism and alcohol use. We then modeled headache status after adjusting for gender, age, race, parental history of headaches, social stratification, and school of origin. We also include in the logistic regression model use of illicit drugs, self-report of maternal hypertension during pregnancy, of duration of pregnancy and of method of delivery.

The level of significance adopted was 5\%. Statistical analysis was performed with the aid of the SPSS 15.0 for Windows (SPSS Inc.; Chicago IL).

This study and the phone survey received full approval from a Human Research Committee (São José do Rio Preto School of Medicine).

\section{RESULTS}

\section{Sample characteristics}

Of the 1,870 consenting participants, complete information allowing to the diagnosis of headache, as well as information on prenatal care, was obtained from 1,440 (77\%). Of the children, 681 were girls $(47.3 \%, 58.9 \%$ White), while 759 were boys (52.7\%, $57.9 \%$ White). Table 1 displays the distribution of age of participants, stratified by gender and race. Contrasting those with complete vs. non-complete responses, proportions did not differ by age or gender (Table 1), but were higher in white than non-white $(\mathrm{p}<0.05)$ Responses did not differ as a function of headache status in the mother or by school of origin.

\section{Headache status}

Table 2 displays the headache status overall and by gender. Episodic headaches were seen in $45.7 \%$ of the sample ( $41.4 \%$ in boys and $46 \%$ in girls, $\mathrm{p}<0.01)$. Chronic daily headaches happened in $1.7 \%$ of the sample $(2.5 \%$ in girls and $1.7 \%$ in boys, $\mathrm{p}<0.05)$. Prevalences of episodic

Table 1. Demographics of study participants.

\begin{tabular}{|c|c|c|c|c|}
\hline & \multicolumn{2}{|c|}{ Complete information } & \multicolumn{2}{|c|}{ Non complete information } \\
\hline & $n=1440$ & $\%$ & $\mathrm{n}=430$ & $\%$ \\
\hline \multicolumn{5}{|l|}{ Gender } \\
\hline Boys & 759 & 52.7 & 219 & 50.9 \\
\hline Girls & 681 & 47.3 & 211 & 49.1 \\
\hline \multicolumn{5}{|l|}{ Race } \\
\hline White & 840 & 58.3 & 236 & 54.8 \\
\hline Non-white & 525 & 36.5 & 172 & $40^{*}$ \\
\hline Not reported & 75 & 5.2 & 22 & 5.2 \\
\hline Age in years (mean $\pm S D$ ) & \multicolumn{2}{|c|}{$7.8(3.1)$} & \multicolumn{2}{|c|}{$7.5(4.1)$} \\
\hline
\end{tabular}

$\mathrm{N}$ : number; SD: standard deviation. ${ }^{*} \mathrm{p}<0.05$. 
Table 2. Headache status among participant children

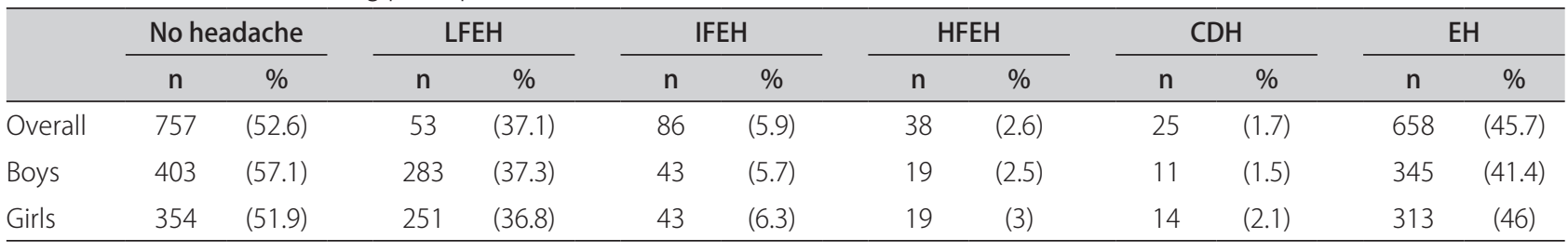

LFEH: low frequency episodic headaches (1-4 days of headache per month); IFEH: intermediate frequency episodic headache (5-9 days of headache per month); HFEH: high frequency episodic headache (10-14 days of headache per month); CDH: chronic daily headaches (15 or more days of headache per month); EH: episodic headaches.

Table 3. Headache status as a function of tabagism during pregnancy in unadjusted analyses.

\begin{tabular}{|c|c|c|c|c|c|c|c|c|}
\hline & \multicolumn{2}{|c|}{ No headache } & \multicolumn{3}{|c|}{ Episodic headaches } & \multicolumn{3}{|c|}{$\mathrm{CDH}$} \\
\hline & $\mathrm{n}$ & $(\%)$ & $\mathrm{n}$ & $(\%)$ & OR $(95 \% \mathrm{Cl})$ & $\mathrm{n}$ & $(\%)$ & OR $(95 \% \mathrm{Cl})$ \\
\hline \multicolumn{9}{|l|}{ Overall } \\
\hline Neither active nor passive tabagism & 146 & $(41.2)$ & 253 & $(38.4)$ & Reference & 4 & $(16)$ & Reference \\
\hline Active + passive & 66 & $(18.6)$ & 142 & $(21.5)$ & $1.15(0.9-1.46)$ & 10 & $(40)$ & $2.29(1.6-3.6)$ \\
\hline Active only & 22 & $(6.2)$ & 30 & $(4.5)$ & $0.81(0.48-1.36)$ & 5 & $(20)$ & $4.2(2.1-8.5)$ \\
\hline Passive only & 120 & $(33.9)$ & 233 & $(35.4)$ & $1.1(0.9-1.2)$ & 6 & $(24)$ & $1.33(0.88-2.25)$ \\
\hline Active or passive & 142 & $(40.1)$ & 263 & (39.9) & $1.13(0.96-1.32)$ & 11 & (44) & $1.55(1.1-2.1)$ \\
\hline \multicolumn{9}{|l|}{ Boys } \\
\hline Neither active nor passive tabagism & 123 & $(30.5)$ & 118 & $(34.2)$ & Reference & 2 & $(18.2)$ & Reference \\
\hline Active + passive & 109 & $(27)$ & 88 & $(25.5)$ & $0.90(0.7-1.1)$ & 4 & $(36.3)$ & $1.4(0.9-2.5)$ \\
\hline Active only & 28 & $(6.9)$ & 19 & $(5.5)$ & $0.73(0.4-1.2)$ & 2 & $(18.2)$ & $2.7(0.95-7.6)$ \\
\hline Passive only & 143 & $(35.5)$ & 120 & $(34.8)$ & $0.93(0.8-1.1)$ & 3 & $(27.3)$ & $0.8(0.4-2.3)$ \\
\hline Active or passive & 171 & $(42.4)$ & 138 & $(40.1)$ & $0.91(0.8-1.1)$ & 5 & $(45.4)$ & $1.2(0.7-1.9)$ \\
\hline \multicolumn{9}{|l|}{ Girls } \\
\hline Neither active nor passive tabagism & 146 & $(41.2)$ & 145 & $(43.1)$ & Reference & 2 & $(14.3)$ & Reference \\
\hline Active + passive & 66 & $(18.7)$ & 54 & $(17.2)$ & $0.87(0.6-1.2)$ & 6 & $(42.9)$ & $2.40(1.5-3.8)$ \\
\hline Active only & 22 & $(6.1)$ & 11 & $(3.5)$ & $0.54(0.3-1.1)$ & 2 & $(14.3)$ & $3.82(1.3-10.9)$ \\
\hline Passive only & 120 & $(33.9)$ & 113 & $(36.1)$ & $0.97(0.9-1.2)$ & 4 & $(28.6)$ & $1.48(0.8-2.6)$ \\
\hline Active or passive & 142 & $(40.1)$ & 124 & $(39.7)$ & $0.93(0.8-1.1)$ & 8 & $(57.1)$ & $1.62(1.2-2.2)$ \\
\hline
\end{tabular}

$\mathrm{CDH}$ : chronic daily headaches ( 15 or more days of headache per month); OR $(95 \% \mathrm{Cl})$ : odds ratio and $95 \%$ confidence interval of the odds ratio. When the $\mathrm{Cl}$ does not include the number 1, the difference is significant and is illustrated by bold and italic numbers. In unadjusted analyses the two-sided chi-squared test was used.

headache subdivisions, as defined in the methods, are also presented in Table 2.

\section{Headache status and tabagism during pregnancy}

We first assessed if headache status (no headache vs. any headache) was associated with tabagism during pregnancy and found no association, overall $(\mathrm{p}=0.87)$ and by gender. Overall, active and passive smoking were seen in $22.5 \%$ of the headache group vs. $23.1 \%$ of the no-headache group; active only was found in $4.9 \%$ and 6.6\%; passive only was found in $35.1 \%$ and $34.7 \%$; active or passive happened in $40.4 \%$ and $41.3 \%$. Differences were not significant.

Differently, when headache status was stratified as no headache, episodic headaches, and $\mathrm{CDH}$, significant dif- ferences were seen overall and by gender. Pooling both genders and taking the no headache group as the reference, odds of $\mathrm{CDH}$ were significantly higher when maternal tabagism was reported. When active and passive smoking were reported, odds ratio (OR) of CDH were 2.29 [95\% confidence intervals $(\mathrm{CI})=1.6 \mathrm{vs.} 3.6)]$; for active (but not passive) tabagism, $\mathrm{OR}=4.2(95 \% \mathrm{CI}=2.1-8.5)$. For passive tabagism, odds were not significantly increased $(\mathrm{OR}=1.33,95 \% \mathrm{CI}=0.88-2.25)$. Finally, when active or passive tabagism happened, odds of $\mathrm{CDH}$ were significantly increased $(\mathrm{OR}=1.55,95 \% \mathrm{CI}=1.2-2.1)$.

Episodic headaches and tabagism were not significantly associated, and odds of $\mathrm{CDH}$ were significantly elevated when active tabagism happened, as compared to episodic headaches (Table 3 ). 
Table 4. Headache status as a function of alcohol use during pregnancy.

\begin{tabular}{|c|c|c|c|c|c|c|c|c|}
\hline & \multicolumn{2}{|c|}{ No headache } & \multicolumn{3}{|c|}{ Episodic headaches } & \multicolumn{3}{|c|}{$\mathrm{CDH}$} \\
\hline & $n$ & $(\%)$ & $\mathrm{n}$ & $(\%)$ & OR $(95 \% \mathrm{CI})$ & $\mathrm{n}$ & $(\%)$ & OR (95\% CI) \\
\hline \multicolumn{9}{|l|}{ Overall } \\
\hline No alcohol & 673 & (89.6) & 627 & $(90.1)$ & Reference & 19 & (76) & Reference \\
\hline Alcohol & 146 & $(11.2)$ & 69 & (9.9) & $0.95(0.7-1.3)$ & 6 & (24) & $2.3(1.2-4.7)$ \\
\hline \multicolumn{9}{|l|}{ Boys } \\
\hline No alcohol & 341 & $(88.2)$ & 324 & (88.8) & Reference & 9 & (81.8) & Reference \\
\hline Alcohol & 46 & $(11.8)$ & 41 & $(11.2)$ & $0.94(0.6-1.4)$ & 2 & $(18.2)$ & $1.53(0.4-5.3)$ \\
\hline \multicolumn{9}{|l|}{ Girls } \\
\hline No alcohol & 352 & $(91.7)$ & 303 & $(91.5)$ & Reference & 10 & $(71.4)$ & Reference \\
\hline Alcohol & 32 & (8.3) & 28 & (8.4) & $1(0.6-1.6)$ & 4 & $(28.6)$ & $3.4(1.4-8.3)$ \\
\hline
\end{tabular}

$\mathrm{CDH}$ : chronic daily headaches (15 or more days of headache per month); OR $(95 \% \mathrm{Cl}$ ): odds ratio and $95 \%$ confidence interval of the odds ratio. When the $\mathrm{Cl}$ does not include the number 1, the difference is significant and is illustrated by bold and italic numbers. In unadjusted analyses the two-sided chi-squared test was used.

After stratifying by gender, similar findings were seen for girls, and non-significant increase of $\mathrm{CDH}$ when active tabagism was reported was seen for boys.

Defining categories differently, as described in the methods, did not alter the findings. Indeed, the odds of all categories of episodic headaches (LFEH, IFEH, and HFEH) were very similar as a function of tabagism category.

\section{Headache status and alcohol use during pregnancy}

As for tabagism, alcohol use during pregnancy was not associated with any headache (headache vs. no headaches in the past year) ( $\mathrm{OR}=0.97,95 \% \mathrm{CI}=0.6-1.4)$. However, it was associated with CDHs (Table 4). Alcohol use more than doubled the chance of $\mathrm{CDH}$ (24\% vs. $11 \%$, $\mathrm{OR}=2.3,95 \% \mathrm{CI}=1.2-4.7$ ), as compared to no-alcohol report. The magnitude of the effect was smaller (and nonsignificantly elevated) in boys ( $18 \%$ vs. $12 \%, \mathrm{OR}=1.53$, $95 \% \mathrm{CI}=0.4-5.3)$ than in girls ( $29 \%$ vs. $8 \%, \mathrm{OR}=3.4,95 \%$ $\mathrm{CI}=1.4-8.3)$. Alcohol use was not associated with any of the episodic headache categories.

\section{Multivariate analyses}

In multivariate analyses, prevalence of $\mathrm{CDH}$ was significantly higher in girls than in boys $(2.2 \%$ vs. $1.4 \%$, $\mathrm{p}<0.05)$, and in non-white vs. white $(2.2 \%$ vs. $1.2 \%$, $\mathrm{p}<0.01)$. Adjustments did not substantially change the prenatal exposure to tobacco/CDH association $(\mathrm{p}<0.01)$. None of the covariates (method of delivery, history of hypertension, etc), significantly contributed to the model. Odds were elevated in both boys $(\mathrm{OR}=1.4,95 \% \mathrm{CI}=1.1$ $2.1)$ and girls $(\mathrm{OR}=3.1,95 \% \mathrm{CI}=1.5-4.2)$, but were significantly more elevated in girls (Table 5 ).

As for alcohol, when prenatal care and income were included in the models (full adjustments), odds were attenuated, but remained strikingly significant overall
Table 5. Main effect of tabagism and alcohol use during pregnancy in chronic daily headaches in childhood after adjustments.

\begin{tabular}{lccc}
\hline & $\begin{array}{c}\text { Overall } \\
\text { OR }(95 \% \mathrm{Cl})\end{array}$ & $\begin{array}{c}\text { Boys } \\
\text { OR }(95 \% \mathrm{Cl})\end{array}$ & $\begin{array}{c}\text { Girls } \\
\text { OR }(95 \% \mathrm{Cl})\end{array}$ \\
\hline Tabagism & $2.03(1.3-3.2)$ & $1.4(1.1-2.1)$ & $3.1(1.5-4.2)$ \\
Alcohol & $1.8(1.3-3.1)$ & $1.2(0.2-3.4)$ & $2.7(1.5-4.1)$ \\
\hline
\end{tabular}

Headache status was modeled overall and stratified by gender using logistic regression. Variables included in the model were race, parental history of headaches, social stratification, and school of origin. Covariates included of illicit drugs, self-report of maternal hypertension during pregnancy, of duration of pregnancy and of method of delivery. OR ( $95 \% \mathrm{Cl}$ ): odds ratio and $95 \%$ confidence interval of the odds ratio. When the $\mathrm{Cl}$ does not include the number 1 , the difference is significant.

and for girls $(\mathrm{OR}=1.8,95 \% \mathrm{CI}=1.3-3.1)$, but not for boys (Table 4).

Use of illicit drug did not contribute to the model.

\section{DISCUSSION}

\section{Overview}

We found that exposure to tobacco and to alcohol in pregnancy were significantly associated with $\mathrm{CDH}$ but not with episodic headaches in both crude and adjusted analyses. Additionally, odds of prenatal exposure to tobacco and alcohol use were significantly increased in $\mathrm{CDH}$ (cases) vs episodic headaches or controls. To the best of our knowledge, other studies investigating prenatal exposures and $\mathrm{CDH}$ during childhood are lacking.

While genetic factors appear to be etiologically significant for several primary headache disorders ${ }^{16}$, the growing body of evidence from population-based family studies and twin studies indicates that genetic factors play a significant but incomplete role in migraine etiolo$\mathrm{gy}^{17}$. For episodic headaches, among the non-genetic factors, hormones and gender specific traits, diet, and response to stress are likely to be significant. For CDHs 
in adults, exposures to certain medications and caffeine, comorbidities, obesity, among others, have been identified as risk factors ${ }^{18}$. Smoking and alcohol intake have been considered as risk factors for relapsing of medication overuse headache in a longitudinal study ${ }^{19}$. In the pediatric population, age of onset and severity of migraine ${ }^{4}$, as well as psychiatric comorbidities ${ }^{6}$ have been associated with $\mathrm{CDH}$. The interface between biological predisposition and exposure is exemplified in an adolescent study. In those with family history of migraine, household income did not have a significant effect, probably because of the higher biologic predisposition. In those without a strong predisposition, household income was associated with prevalence ${ }^{5}$.

\section{Tabagism during pregnancy and frequent headaches at childhood}

The influence of tobacco exposure on intrauterine development is well demonstrated in animals and humans $^{20,21}$. Preclinical studies, using primarily rodent models, have shown acetylcholine to have a critical role in brain maturation via activation of nicotinic acetylcholine receptors (nAChRs). In humans, exposure of fetal and neonatal brain to nicotine, through maternal smoking or nicotine replacement therapy, has been shown to have detrimental effects on cholinergic modulation of brain development. Furthermore, a neuroimaging study found decreased cortical thickness in female adolescents exposed intra-utero to maternal smoking.

Among the several toxics of tobacco, nicotine may influence pain transmission through several ways. First, the contents of the monoamines and metabolites, including noradrenaline, dopamine, and serotonin, seem to be increased in offspring exposed to prenatal nicotine. Dopamine and serotonin are directly involved in the modulation of pain transmission in migraine ${ }^{22}$. At a peripheral level, a decrease in nitric oxide production ${ }^{23}$ and increased platelet aggregation (with consequence release of histamine and stimulation of serotoninergic pathways $)^{24}$ have been proposed as well.

\section{Alcohol exposure during pregnancy and frequent headaches in childhood}

Certain aspects of the relationship between alcohol intake and headaches are well established. For example, alcohol is a potent cluster headache trigger ${ }^{25}$, and red wine is one of the most frequently reported migraine triggers ${ }^{26}$. However, very little is known about the effects of prenatal alcohol exposure and pain. Indeed, ethanol has known analgesic and sedative properties, and ethanol withdrawal is associated with hyperalgesia. Furthermore, it has been demonstrated that neither acute nor chronic exposure to ethanol affect incisional pain in neonatal rats $^{27}$. Nonetheless, the effects of ethanol on somatosensory processing are dependent upon the age at which exposure occurs ${ }^{28}$. Indeed, it has been proposed that during the prenatal phase, significant alterations occur in pain processing pathways after even minor exposures to ethanol, and that early ethanol exposure may alter the maturation of somatosensory pathways and hence alter nociceptive responses at later time points. It has been speculated that even brief ethanol exposure exerts a priming effect on certain areas involved with analgesia.

\section{Caveats and strengths}

Our study has limitations. First, although populational, sample came from a single city. However, as exposed in the methods, the city is similar to Brazil by demographics; furthermore, we conduct adjusted analyses, which limit the potential sample bias. Second, probands were identified through their registration in the public school system. Although this is a well-established method to investigate the epidemiology of diseases in the pediatric population, since education is mandatory in most countries, there is a theoretical risk that we missed children not being educated at school. More important is the fact that children from higher socioeconomic strata are less likely to study in the public school system, and adjustments would not perfectly address this topic, since the socioeconomic variables would be shifted toward the lower incomes. Since low income is a risk factor for headache frequency in the pediatric population ${ }^{5}$, and also to tabagism ${ }^{29}$ and use of alcohol $^{30}$, there is a risk that we overestimated the prevalences. Confirmatory data is necessary. Third, our questionnaire did not allow us to obtain metrics of magnitude of exposure (number of cigarettes or amount of alcohol intake over a period of time). Finally, information was self-reported and for this item, a bias on the opposite direction of the income may have acted, therefore leading to underestimating the associations (since patients may have under-reported exposures leading to a social desirability bias).

Strengths of our study include the population nature, robustness of sample, use of well-developed and validated questionnaires, and utilization of direct interviews (for applying the questionnaires). Furthermore, the case-control design allows the inference of causal attribution.

In conclusion, prenatal exposure to tobacco and ethanol are associated with increased of $\mathrm{CDH}$ before adolescence. The risk remains significantly elevated after adjusting for family income, parental headache status, medical care during pregnancy, hypertension during pregnancy and use of illegal drugs. Studies should focus on the relevance of toxic exposures during pregnancy to the development of chronic pain later in life, on the efficacy of preventive strategies to mitigate the risk of exposure, and on 
the adequacy of therapeutic strategies to adequately identify and treat children at increased risk to $\mathrm{CDH}$.

\section{REFERENCES}

1. Arruda M, Guidetti V, Galli F, Bigal ME. Chronic daily headaches and high frequency episodic headaches in the pre-adolescent pediatric population: a population-based study. Neurology 2010;74:903-908.

2. Hershey AD, Gladstein J, Winner P. Chronic daily headache in the pediatric population. Curr Treat Options Neurol 2007:9:14-22.

3. St George-Hyslop PH, Petit A. Molecular biology and genetics of Alzheim er's disease. C R Biol 2005:328:119-130.

4. Bigal ME, Lipton RB, Tepper SJ, Rapoport AM, Sheftell FD. Primary chronic daily headache and its subtypes in adolescents and adults. Neurology 2004; 63:843-847.

5. Bigal ME, Lipton RB, Winner P, Reed ML, Diamond S, Stewart WF. Migraine in adolescents: association with socioeconomic status and family history. Neurology 2007;69:16-25.

6. Galli F, Patron L, Russo PM, Bruni O, Ferini-Strambi L, Guidetti V. Chronic daily headache in childhood and adolescence: clinical aspects and a 4-year follow-up. Cephalalgia 2004;24:850-858.

7. Brent RL, Tanski S, Weitzman M. A pediatric perspective on the unique vulnerability and resilience of the embryo and the child to environmental toxicants: the importance of rigorous research concerning age and agent. Pediatrics 2004;113:935-944

8. Slotkin TA. Fetal nicotine or cocaine exposure: which one is worse? J Pharmacol Exp Ther 1998;285:931-945

9. Handmaker NS, Rayburn WF, Meng C, Bell JB, Rayburn BB, Rappaport VJ. Impact of alcohol exposure after pregnancy recognition on ultrasonographic fetal growth measures. Alcohol Clin Exp Res 2006:30:892-898.

10. Aamodt AH, Stovner $L$, Hagen K, Brathen G, Zwart J. Headache prevalence related to smoking and alcohol use. The Head-HUNT Study. Eur J Neurol 2006;13:1233-1238

11. Mannix LK, Frame JR, Solomon GD. Alcohol, smoking, and caffeine use among headache patients. Headache 1997;37:572-576.

12. Arruda M. Projeto atencao Brasil [online]. Available at: http://www.atencao brasil.com.br/. Accessed 07/2009.

13. IBGE IBdGeE-. Estatistica da Populacao Brasileira [online]. Available at: http://www.ibge.gov.br/home/estatistica/populacao/estimativa2008/ POP2008_DOU.pdf. Accessed 07/2009.

14. Society. HCSotlH. The International Classification of Headache Disorders. $2^{\text {nd }}$ Edition. Cephalalgia 2004;24:1-149.
15. Godoy DAG, Bigal ME, Jales LCF, Camparis CM, Speciali JG. Headache and symptoms of temporomandibular disorder: an epidemiological study. Headache 2009;50:231-241.

16. Ferrari MD. Migraine genetics: a fascinating journey towards improved migraine therapy. Headache 2008;48:697-700

17. Ulrich V, Gervil M, Fenger K, Olesen J, Russell MB. The prevalence and characteristics of migraine in twins from the general population. Headache 1999; 39:173-180.

18. Bigal ME, Lipton RB. Modifiable risk factors for migraine progression. Headache 2006;46:1334-1343

19. Sances G, Ghiotto N, Galli F, et al. Risk factors in medication-overuse headache: a 1-year follow-up study (care II protocol). Cephalalgia 2009 Jul 13. [Epub ahead of print]

20. Tolcos M, Mallard C, McGregor H, Walker D, Rees S. Exposure to prenatal carbon monoxide and postnatal hyperthermia: short and long-term effects on neurochemicals and neuroglia in the developing brain. Exp Neurol 2000;162:235-246

21. Ernst M, Moolchan ET, Robinson ML. Behavioral and neural consequences of prenatal exposure to nicotine. J Am Acad Child Adolesc Psychiatry 2001; 40:630-641.

22. Goadsby PJ, Hargreaves RJ. Mechanisms of action of serotonin 5-HT1B/D agonists: insights into migraine pathophysiology using rizatriptan. Neurology 2000;55(Suppl):S8-S14

23. Lassen LH, Ashina M, Christiansen I, Ulrich V, Olesen J. Nitric oxide synthase inhibition in migraine. Lancet 1997:349:401-402.

24. Ferrari MD, Odink J, Frolich M, Tapparelli C, Portielje JE. Release of platelet Met-enkephalin, but not serotonin, in migraine: a platelet response unique to migraine patients? J Neurol Sci 1989;93:51-60.

25. Evans RW, Schurks M. Alcohol and cluster headaches. Headache 2009;49: 126-129.

26. Littlewood JT, Gibb C, Glover V, Sandler M, Davies PT, Rose FC. Red wine as a cause of migraine. Lancet 1988;1:558-559.

27. Shumilla JA, Liron T, Mochly-Rosen D, Kendig JJ, Sweitzer SM. Ethanol withdrawal-associated allodynia and hyperalgesia: age-dependent regulation by protein kinase C epsilon and gamma isoenzymes. J Pain 2005;6:535-549.

28. Shumilla JA, Sweitzer SM, Kendig JJ. Acute and chronic ethanol exacerbates formalin pain in neonatal rats. Neurosci Lett 2004;367:29-33.

29. Jia H, Lubetkin El. The statewide burden of obesity, smoking, low income and chronic diseases in the United States. J Public Health (Oxf) 2009:31:496-505

30. Elgar FJ, Roberts C, Parry-Langdon N, Boyce W. Income inequality and alcohol use: a multilevel analysis of drinking and drunkenness in adolescents in 34 countries. Eur J Public Health 2005;15:245-250. 